Expert Opin Pharmacother. 2016 August ; 17(11): 1549-1559. doi:10.1080/14656566.2016.1183648.

\title{
Budesonide for the Treatment of Ulcerative Colitis
}

\author{
Maisa I. Abdalla, MD, MPH ${ }^{1}$ and Hans Herfarth, MD, PhD' \\ ${ }^{1}$ Department of Medicine, Division of Gastroenterology and Hepatology, University of North \\ Carolina at Chapel Hill
}

\begin{abstract}
Introduction-Budesonide is a synthetic corticosteroid characterized by enhanced topical potency and limited systemic bioavailability. Its use in ulcerative colitis (UC) was limited to rectal preparations until recently when the new oral budesonide formulation incorporating the multimatrix system technology was introduced. The purpose of this review is to evaluate the current role of oral and rectal budesonide in managing UC patients
\end{abstract}

Areas Covered-In this paper, we described the chemical structure and pharmacologic characteristics of the different oral and rectal budesonide preparations, provided a summary of the published trials that evaluated the efficacy and safety of budesonide in UC, and discussed the current status of its use in this population

Expert Opinion-Budesonide is effective in inducing remission in a subset of patients with mild-moderate UC. Nevertheless, the current evidence suggests inferiority of oral budesonide to 5aminosalisylates (5-ASA) and systemic steroids, whereas rectal applications are comparable to other rectal steroid preparations but still inferior to rectal 5-ASA. In clinical practice, several issues need clarification including, its exact position in the line of induction agents; the role of combining budesonide and 5-ASAs; the role of combining oral and rectal budesonide; and the role of budesonide in maintenance therapy.

\section{Keywords}

Ulcerative colitis; inflammatory bowel disease; budesonide; steroids

\section{Introduction}

Ulcerative colitis (UC) is a form of inflammatory bowel disease (IBD) characterized by diffuse mucosal inflammation that invariably involves the rectum and extends proximally to variable lengths in the colon. UC is a chronic disease with a remitting-relapsing nature and hence, the goal of therapy is to induce remission and to prevent relapses. Systemic corticosteroids were amongst the first therapies used in the treatment of UC. Their efficacy in inducing remission is well-established from the earlier clinical trials in 1950s and 1960s with clinical response rates approaching $80 \%$ in some studies. ${ }^{1-3}$ Those results are further

Corresponding Author: Hans Herfarth, MD, PhD, Professor of Medicine, University of North Carolina, Department of Medicine, Division of Gastroenterology and Hepatology, CB\# 7080, 130 Mason Farm Road, 4151 Bioinformatics Bldg., Chapel Hill, NC, 27599, Phone: (001)-919-966-6806, Fax: (001)-919-966-7592, hherf@med.unc.edu.

Disclosures: HH serves as a consultant for BMS and Janssen. MA: no disclosures. 
supported by the clinical experience over the last half century. ${ }^{4-7}$ The impact of corticosteroids on the immune response is carried through their interaction with the intracytoplasmic glucocorticoid receptors. This interaction results in downregulation of several proinflammatory cytokines and subsequent inhibition of inflammatory cells proliferation and recruitment. ${ }^{8,9}$ However, the powerful anti-inflammatory effect of corticosteroids is counterbalanced by the long list of well-recognized complications associated with systemic corticosteroids. Furthermore, corticosteroids have not been shown to reduce the risk of disease relapse when used as a maintenance therapy. ${ }^{1,10}$ Thus, the only indication for the use of systemic corticosteroids in UC is to induce remission in moderate to severe cases. ${ }^{6}$ To ameliorate or prevent steroid associated side effects, a "second generation" of topically acting corticosteroids characterized by higher potency and lower systemic bioavailability was developed. ${ }^{11}$ Budesonide is considered the prototype of the topically acting corticosteroids and the most extensively studied form in IBD. It is recommended as first line therapy for induction of remission in Crohn's disease (CD) patients with mildmoderate disease, particularly those with disease distribution involving the distal ileum and/or right colon. ${ }^{12,13}$ Nevertheless, its role in UC patients is not as established. The purpose of this report is to evaluate the current status of budesonide use in $\mathrm{UC}$ and to discuss some of the concerns associated with its use in clinical practice.

\section{Overview of the market}

The estimated annual incidence of UC is 24.3 per 100,000 person-years in Europe and 19.2 per 100,000 person-years in North America. ${ }^{14}$ It affects approximately 500,000 individuals in USA. ${ }^{15}$ Until recently, therapeutic options for mild-moderate UC were limited to oral and rectal 5-aminosalisylates (5-ASA) preparations and rectal corticosteroids preparation. Patients who fail those therapies are frequently treated with systemic corticosteroid to induce remission and may require escalation to immunomodulator and biologic therapies to maintain remission. The oral extended release formulation as well as rectal application of budesonide was recently approved by the US Food and Drug Administration (FDA) for induction of remission in patients with mild to moderate $\mathrm{UC}$, which expanded the therapeutic options for this subpopulation. ${ }^{16,17}$

\section{What is Budesonide?}

Budesonide is a synthetic, non-halogenated corticosteroid that is structurally related to $16 \mathrm{a}$ hydroxyprednisolone. It includes asymmetric $16 a, 17 a-$ acetyl groups resulting in a 1:1 mixture of two epimers labeled as $22 \mathrm{R}$ and $22 \mathrm{~S}$ [figure 1]. ${ }^{18,19}$ Both epimers are biologically active with similar terminal half-life of $2.7 \pm 0.6 \mathrm{~h}$. However, the $22 \mathrm{R}$ epimer is $2-3$ times more potent than its counterpart and has higher distribution volume and clearance. ${ }^{18}$ This chemical structure accounts for the favorable characteristics of budesonide including its increased affinity to corticosteroid receptors and enhanced topical potency, which approaches 5 times that of the prednisone. ${ }^{19,20}$ It also allows for the rapid clearance of the drug through an extensive first-pass metabolism in the liver with a resultant low systemic bioavailability minimizing its systemic effects. ${ }^{20}$ 
In its native form, budesonide is rapidly absorbed in the proximal gastrointestinal tract and cleared through the liver. This poses a challenge for its use in UC as for topically acting steroids, drug delivery to the site of inflammation is critical. Several drug delivery mechanisms have been incorporated to allow targeted budesonide release and currently three oral formulations of budesonide are commercially available [table 1]:

I. $\quad \mathrm{PH}$-dependent-release formulation designed to deliver the drug at $\mathrm{PH} \geq 6.4$ (Budenofalk ${ }^{\circledR}$ Dr. Falk pharm, Freiburg Germany),

II. PH-dependent and time-dependent controlled- release formulation designed to dissolve at PH $\geq 5.5$ (Entocort ${ }^{\circledR}$ AstraZeneca, Lund Sweden),

III. Multimatrix (MMX) formulation consistent of tablets with three matrix layers designed to release budesonide homogenously throughout the ascending, transverse and descending colon $\left(\right.$ Uceris $^{\circledR}$ Santarus, Inc. CA. USA)

In addition, for proctitis and left-sided colitis, rectal formulations of budesonide are

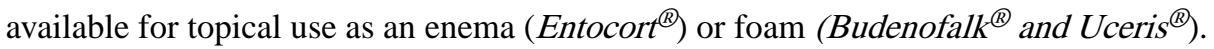

\section{Pharmacokinetics}

After oral administration, budesonide is released starting in the proximal jejunum (Entocort ${ }^{\circledR}$ ), ileum (Budenofalk ${ }^{\circledR}$ ), or homogenously throughout the ascending, transverse and descending colon (Uceris $\left.{ }^{\circledR}\right) .{ }^{21-23}$ Once released, the apical enterocyte drug transporter, P-glycoprotein, facilitates its absorption to be rapidly metabolized via the cytochrome P450 isoenzymes CYP3A4 and CYP3A5 expressed in the liver and, to a lesser extent, in the intestinal epithelial cells. ${ }^{24,25}$ The products of budesonide metabolism, $16 \mathrm{a}-$

hydroxyprednisolone and $6 \beta$-hydroxybudesonide have negligible corticosteroid activity compared to their parent compound and do not contribute to its therapeutic effect [figure 1]. They are primarily cleared through the kidneys but small fraction is conjugated and excreted in the bile. ${ }^{24,26}$ About $90 \%$ of the orally administered budesonide undergo first-pass metabolism resulting in a low systemic bioavailability of $10-15 \% .{ }^{26}$ Furthermore, most of the systemically available budesonide is bound to plasma proteins (88\%). ${ }^{27}$ Apart from the differences in the site and rate of drug release, the different oral budesonide formulations share similar pharmacokinetic characteristics [table 1]. ${ }^{21,28-34}$ Likewise, the two rectal formulations share similar pharmacokinetics, although the foam is characterized by less proximal spread and takes longer time to reach peak plasma concentration [table 1].

Several factors have been shown to impact the clearance and systemic bioavailability of budesonide through interference with its metabolism. For instance, the presence of liver cirrhosis was associated with 2.5 -fold increase in systemic bioavailability of the controlledrelease budesonide formulation. ${ }^{29}$ Likewise, concomitant use of ketoconazole or grapefruit juice, both act as inhibitors of cytochrome P450 isoenzymes, resulted in significant increase of budesonide systemic bioavailability. ${ }^{35,36}$ In addition, altered gastrointestinal motility or PH may interfere with budesonide release after oral administration. For example, the time to detect drug concentration in the plasma $\left(\mathrm{T}_{\mathrm{lag}}\right)$ and the time to achieve maximum concentration $\left(\mathrm{T}_{\max }\right)$ were significantly increased in healthy volunteers given a dose of 
budesonide-MMX after a high-fat, high-calorie meal compared to those who received the drug while fasting. ${ }^{22}$ Post-prandial gastric emptying delay was suggested as a potential cause for the reduced absorption rate. Administering budesonide with food may also enhance its clearance given post-prandial increase in splanchnic circulation blood flow. Of note, neither the patient's age nor the gender had an impact on budesonide metabolism and clearance. $^{29}$

\section{Clinical Efficacy}

\subsection{Oral budesonide for induction of remission in UC}

Earlier studies did not provide adequate evidence to support the use of oral budesonide in patients with UC and traditionally, only rectal budesonide preparations were considered as a potential therapy option in this population. ${ }^{6}$ In a systemic review of Cochrane database published in 2010, three clinical trials addressing the role of oral budesonide in UC met the criteria for the review and were critically assessed (Löfberg 1996, Gross 2011, and D'Haens 2010) [table 2]. ${ }^{37}$ The three studies varied in regard of the comparator medication (prednisolone in one study, mesalamine in the second and placebo in the third), budesonide formulation used, and the assessed primary outcomes. ${ }^{38-40}$ This review concluded that the evidence is not adequate to recommend the clinical use of oral budesonide for the induction of remission in active UC. Furthermore, mesalamine was superior to budesonide ( $\mathrm{ph} \geq 6.4$ dependent release formulation; Budenofalk ${ }^{\circledR}$ ) in this population. However, several recent trials using budesonide-MMX formulation showed more encouraging results reviving the interest in utilizing this compound in UC patients. ${ }^{41-43}$

The initial pilot study by D'Haens et al. (included in the above mentioned Cochrane review) did not show significant difference in rates of clinical remission between budesonide-MMX $9 \mathrm{mg}$ and placebo (47.1\% vs. $33.3 \%$, respectively. P-value 0.14$).{ }^{40}$ This study included a small number of patients $(n=36)$ and the disease distribution was limited to left-sided colitis. Subsequently, two larger, identically designed phase III clinical trials, CORE I and CORE II were conducted. ${ }^{41,42}$ In CORE I, 509 patients with active mild-moderate UC were randomized to four arms; budesonide-MMX 9mg/day, budesonide-MMX 6mg/day, mesalamine $2.4 \mathrm{~g} /$ day $\left(\right.$ Asacol $^{\circledR}$ Warner Chilcott plc. Dublin, Ireland), or placebo. The primary outcome was combined clinical and endoscopic remission at 8 weeks, which was achieved in $17.9 \%, 13.2 \%$, and $12.1 \%$ of patients treated with budesonide-MMX 9mg, budesonide-MMX 6mg, and mesalamine, respectively, compared to $7.4 \%$ in the placebo group. The therapeutic advantage compared to placebo was only significant for budesonideMMX $9 \mathrm{mg}(\mathrm{P}=0.0143)$. Interestingly, there was no significant difference in rates of remission between the budesonide-MMX groups and the mesalamine group. This is contrary to the results from the earlier trial by Gross et al., which compared the efficacy of (PHdependent release) budesonide ( $9 \mathrm{mg} /$ day) to oral mesalamine $(3 \mathrm{~g} /$ day) and concluded that budesonide is inferior to mesalamine. ${ }^{39}$ The two studies used different primary outcome (clinical remission in Gross et al study vs. combined endoscopic and clinical remission in CORE I) and different mesalamine dosages ( $3 \mathrm{~g}$ vs $2.4 \mathrm{~g}$ ), both factors and the different budesonide formulations may have contributed to the inconsistent results. Furthermore, the CORE I trial was not sufficiently powered to detect differences between the active 
compactor groups. A similar study design was applied in CORE II except for the use of controlled-release budesonide (Entocort ${ }^{\circledR}$ ) as the third comparator group instead of mesalamine. ${ }^{42} \mathrm{~A}$ total of 511 patients with mild-moderate active UC were randomized in this study. The rates of combined clinical and endoscopic remission were $17.4 \%, 8.3 \%$, $12.6 \%$, and $4.5 \%$ for the budesonide-MMX 9mg, budesonide-MMX 6mg, Entocort, and placebo groups, respectively. The therapeutic advantage compared to placebo was only significant for budesonide-MMX $9 \mathrm{mg}$ (p-value 0.005). The remission rate amongst patients treated with budesonide-MMX 9mg was comparable to those who received Entocort. However, similar to CORE I, this study was not powered to detect differences between the active comparator groups. Combining the efficacy data from COREI and COREII, budesonide-MMX 9mg was associated with $17.7 \%$ remission rate (clinical and endoscopic) compared to $6.2 \%$ for placebo [OR 3.3, 95\% CI 1.7-6.4 with number needed to treat (NNT) of 8.7] [figure 2]. ${ }^{44}$ An additional study by Rubin et al assessed the efficacy of budesonideMMX $9 \mathrm{mg}$ in patients who had inadequate response to oral 5-ASA compounds. The results from this trial are currently available in an abstract format only. In this study, a total of 510 patients with inadequate response to therapeutic dose of oral 5-ASA compounds, were randomized to receive budesonide-MMX $9 \mathrm{mg}$ or placebo for 8 weeks. ${ }^{43}$ The primary endpoint was combined endoscopic and clinical remission at 8 weeks, which was achieved in $13 \%$ of the budesonide-treated patients vs. $7.5 \%$ for placebo $(\mathrm{p}=0.049)$ [figure 2].

A pooled analysis of data from CORE I, CORE II, and the study by Rubin et al, was recently presented in the updated Cochrane review. ${ }^{45}$ Budesonide-MMX was noted to be significantly superior to placebo for inducing combined clinical and endoscopic remission, $15 \%$ vs. $7 \%$, respectively [RR $2.25,95 \%$ CI 1.50 to 3.39 . NNT of 12.5 ]. Furthermore, subgroup analysis suggested higher efficacy in patients who were not considered to be mesalamine refractory [RR 2.89,95\%CI 1.59-5.25. NNT of 8.3] and those with left-sided disease only [RR $2.98,95 \%$ CI 1.56-5.67. NNT of 7.1].

\subsection{Oral budesonide for maintenance of remission in UC}

Sandborn et al evaluated the efficacy of extended budesonide-MMX use in patients with UC who were in clinical and endoscopic remission at the end of the induction phase of CORE I and CORE II clinical trials. ${ }^{46}$ A total of 122 patients were randomized to receive budesonide-MMX $6 \mathrm{mg}$ or placebo for 12 months. The primary outcome was the proportion of patients in clinical remission after 1, 3, 6, 9, 12 months and/or end of the study and the secondary outcome was time to relapse. No significant difference was noted between budesonide and placebo in regard of the primary outcome. However, in an intention to treat analysis, the probability of clinical relapse was reduced in the budesonide-treated group compared to placebo, $40.9 \%$ vs. $59.7 \%$, respectively. In addition, the median time for relapse was longer in the budesonide-treated patients. The rates of adverse events were comparable between the 2 groups. Those results are currently published in an abstract form only. Hence, the details about of the patients' characteristics, disease distribution and concomitant therapies are not available. In a smaller pilot study by Keller et al, patients with steroiddependent UC were treated with oral (PH-dependent) budesonide $9 \mathrm{mg}$ for 6 months while attempting to taper the conventional corticosteroid. ${ }^{47}$ Of the 14 patients included in the study, a total of $11(78.6 \%)$ were able to terminate the conventional corticosteroids within 3 
months of starting the budesonide. Those results were not replicated in a larger studies or in the context of the current advances in UC medical therapies.

Overall, while it appears to be safe, there is no sufficient evidence to support the use of oral budesonide for maintenance of therapy in UC patients.

\subsection{Rectal budesonide formulations in UC}

The role of rectal budesonide formulations (enema and foam) in left-sided UC is more established. Several studies have been published since 1987 comparing rectal budesonide to placebo, conventional rectal steroid preparations (prednisolone, methylprednisolone, and hydrocortisone), and rectal 5-ASA compounds [table 3]. Compared to placebo, rectal budesonide has consistently shown superior efficacy in treating left-sided UC regardless of form used and the assessed endpoint in each particular study. ${ }^{48-51}$

The standard dose in the commercially available rectal budesonide preparations is $2 \mathrm{mg}$ / application, which is the dose utilized in the majority of the clinical trials evaluating rectal budesonide in UC. Moreover, in a dose finding trial by Hanauer et al comparing the efficacy of 3 budesonide enema preparations $(0.5 \mathrm{mg} / 100 \mathrm{ml}, 2 \mathrm{mg} / 100 \mathrm{ml}$, and $8 \mathrm{mg} / 100 \mathrm{ml})$ to placebo, the $2 \mathrm{mg}$ and $8 \mathrm{mg}$ doses showed equivalent efficacies in improving endoscopic inflammation grades, total histopathology scores, and clinical remission rates. ${ }^{49} \mathrm{In}$ addition, both doses were superior to the $0.5 \mathrm{mg}$ budesonide dose and to the placebo suggesting that 2 $\mathrm{mg}$ is the lowest effective dose. In term of the dose intervals, two studies investigated whether BID dosing is superior to QD dosing in inducing remission. ${ }^{51,52}$ Lindgren et al compared the remission rates (clinical and endoscopic) in patients with active left-sided UC treated with either budesonide enema $2 \mathrm{mg}$ BID or QD for 8 weeks. ${ }^{52}$ The 2 groups had comparable remission rates (54\% vs. $41 \%$ for the BID and QD dosing groups, respectively). More recently, Naganuma et al, investigated whether budesonide foam at BID dosing for 4 weeks is superior to QD dosing in patients with active proctitis or proctosigmoiditis. ${ }^{51}$ While the BID dosing was associated with higher rates of complete mucosal healing, defined as endoscopic subscore of $0(46.4 \%, 23.6 \%$, and $5.6 \%$, for BID, QD and placebo groups, respectively), the two active therapy groups were comparable in achieving clinical remission and endoscopic subscore $\leq 1$. As it remains unclear and highly debatable, whether complete mucosal healing offer significant advantage over endoscopic and clinical remission and based on the available evidence, QD dosing seems to be appropriate. Of note, in two recent trials assessing the efficacy of budesonide foam in active proctitis or proctosigmoiditis and resulted in recent FDA approval, the active therapy group received budesonide foam BID for 2 weeks and then daily for another 4 weeks. ${ }^{50}$ Therefore, this was the recommended dose in the FDA approval letter. ${ }^{17}$

Compared to budesonide enema, budesonide foam has lower volume per application and higher viscosity enhancing patient's tolerability and retention. Gross et al compared the efficacy of budesonide enemas vs. budesonide foam in inducing clinical remission in patients with active proctitis and proctosigmoiditis. ${ }^{53}$ The two forms showed comparable efficacy (60\% vs. 66\% for the foam and enema, respectively) and both preparations were safe and neither caused significant drop in cortisol level. However, more patients preferred the foam preparation. 
In comparison with conventional rectal steroid preparations, budesonide enema has been shown to have equivalent efficacy in treating active left-sided UC. ${ }^{54-59}$ Lastly, 2 studies compared the efficacy of budesonide enema to 5-ASA enema and showed that rectal 5-ASA is superior to rectal budesonide in inducing clinical remission in patients with left-sided UC. ${ }^{60,61}$

To date, only one study assessed the role of rectal budesonide as a maintenance therapy. In the abovementioned trial by Lindgren et al, patients who were in remission at the end of the induction period entered a maintenance phase and were randomized to receive either budesonide enema twice weekly or placebo for 24 weeks. Relapse rate at 24 weeks was comparable between the 2 groups ( $41 \%$ vs. $51 \%$ for the budesonide and placebo groups, respectively). ${ }^{52}$

\section{Safety}

Budesonide, in both oral and rectal formulations, has been repeatedly shown to have an excellent safety profile even with long term use. In the recent Cochrane review that evaluated the role of oral budesonide in UC, pooled analysis of three studies (CORE 1, CORE II, and Rubin et al- total of 971 participants) showed no statistically significant difference between budesonide-MMX 9mg and placebo in the proportion of patients who experienced at least one adverse event [RR 1.09, 95\% CI 0.95-1.26]. ${ }^{45}$ In addition, based on pooled data from CORE I and CORE II trials, the rate of serious adverse events was comparable between budesonide-MMX 9mg and placebo [RR 0.88, 95\% CI 0.33-2.40]. ${ }^{45}$ Furthermore, the rates of adverse events with long term budesonide use in the oral maintenance study by Sandborn et al and the rectal enema study by Lindgren et al were comparable to placebo. ${ }^{46,52} \mathrm{~A}$ dose-dependent reduction in plasma cortisol levels have been noted with both oral and rectal budesonide formulations. Nevertheless, the cortisol levels remained within the normal range in most of the studies and did not seem to have an impact on the rate of corticosteroid-related adverse events. ${ }^{34,45,50,62}$

\section{Regulatory Affairs}

- $\quad$ Oral budesonide-MMX (Uceris ${ }^{\circledR}$ ) received FDA approval on January 14, 2013 for the use in patients with active mild-moderate UC. The recommended dosage is $9 \mathrm{mg}$ daily for up to 8 weeks. ${ }^{16}$

- $\quad$ Budesonide rectal foam $\left(\right.$ Uceris $\left.^{\circledR}\right)$ received FDA approval on October 7, 2014 for the use in patients with active mild-moderate distal UC (up to $40 \mathrm{~cm}$ from the anal verge). The recommended dosage is $2 \mathrm{mg}$ twice daily for 2 weeks, then $2 \mathrm{mg}$ daily for 4 weeks. ${ }^{17}$

\section{Conclusion}

Budesonide, in its oral and rectal format, is effective for induction of remission in a subset of patients with mild-moderate UC. Thus far, oral budesonide has no proven superiority to oral 5-ASAs and is notably inferior to systemic steroids. Hence, the exact position in the line of induction regimens for patients with active UC remains unclear. The role of rectal 
budesonide is managing distal UC is more established with comparable efficacy to other rectal steroid preparations but yet suggested inferiority to rectal 5-ASA preparations. Based on the currently available data, budesonide (oral and rectal preparations) has no role in the maintenance of remission for UC patients.

\section{Expert Opinion/Conclusion}

In the era of expanding biologic therapies, budesonide has emerged as an attractive therapeutic option with excellent safety profile for patients with mild to moderate UC. The efficacy of oral budesonide-MMX in inducing clinical and endoscopic remission has been shown in several large, well-designed, clinical trials. ${ }^{41-43}$ Furthermore, for patients with leftsided colitis, rectal budesonide preparations were superior to placebo and comparable to conventional rectal steroid preparations. ${ }^{48-52,54-59}$ Despite the proven efficacy of budesonide, 5-ASAs remain the first line option and the treatment of choice for patients with mild-moderate UC. This is mainly driven by the extensive evidence supporting the efficacy of 5-ASAs in this population and the earlier studies that revealed superiority of 5-ASAs when compared to budesonide in rectal and controlled-release oral preparations. ${ }^{39,60,61}$ Consequently, many experts have suggested positioning budesonide ahead of systemic steroids in patients with mild-moderate UC who had inadequate response to an appropriate dose of a 5-ASA agent. ${ }^{15,63-65}$ Nevertheless, several questions remained to be explored in order to better understand how to best incorporate this therapy in clinical practice. One in particular is whether there is the role of combining oral budesonide and oral 5-ASAs. Concomitant 5-ASAs were not allowed in the 2 pivotal budesonide-MMX trials (CORE I and CORE II). ${ }^{41,42}$ The study by Rubin et al required inadequate response to 5-ASA monotherapy as criteria for entering the study and budesonide-MMX was an added therapy. ${ }^{43}$ As mentioned above $13 \%$ of the patients randomized to receive budesonide-MMX were able to achieve clinical remission supporting the notion of using budesonide as an addon therapy when 5-ASAs fail to achieve complete remission. However, the efficacy of budesonide-MMX appears to be lower in those who have failed 5-ASAs raising a question about a potential added benefit for upfront use of combined budesonide and 5-ASAs, which theoretically may impact the rate of remission and/or the time to achieve remission. Likewise, there are no data on combining rectal 5-ASAs and rectal budesonide for patients with left-sided colitis. A second question, which has not been addressed in any of the aforementioned studies, is whether there is an added benefit for the induction of remission in combining oral and rectal budesonide, similar to what has been shown with 5-ASAs. ${ }^{66}$ The role of budesonide in maintaining remission is also in question. The current data do not support the use of budesonide as a maintenance therapy in UC. In the maintenance study by Sandborn et al, there was no significant difference between budesonide-MMX $6 \mathrm{mg}$ and placebo in regard of the primary outcome (clinical remission after 1, 3, 6, 9, 12 months and/or end of the study). ${ }^{46}$ However, the probability of clinical relapse was significantly lower and the time to relapse was longer in the budesonide group suggesting potential benefit. These results seem to be comparable to trials evaluating the ability of budesonide to maintain remission in $\mathrm{CD}$, which revealed no difference between placebo and budesonide in maintaining remission after 12 months but in some trials a nominally longer time period to relapse in patients treated with budesonide. ${ }^{67}$ One more area to explore is whether a 
transient use of higher budesonide doses has an additional benefit for some patients. Trials comparing the efficacy of budesonide at different doses in inducing remission in patients with CD revealed similar efficacy of the various budesonide doses $(6,9$, or $18 \mathrm{mg} /$ day) in patients with mild ileo/right colonic disease location, whereas higher doses of budesonide (Budenofalk ${ }^{\circledR} ; 18 \mathrm{mg}$ ) increased the therapeutic response in patients with highly active disease (CDAI > 300) or ileal disease with additional distal colonic manifestation. ${ }^{68}$ Thus a "budesonide taper" starting with $18 \mathrm{mg}$ for e.g. 2 weeks before reducing the dose to $9 \mathrm{mg}$ may ultimately yield better results with only a minor increase in steroid induced side effects. But this approach should be tested first in controlled trials with systemic steroids in the comparator arm, particularly as the potentially enhanced efficacy of the higher budesonide dose may be attributed in part to a higher degree of systemic effects.

While there was no direct comparison to systemic steroids, the efficacy of budesonide MMX to induce clinical remission appears to be clearly inferior to systemic steroids in inducing remission in patients with ulcerative colitis (NNT 12.5 vs. 2, respectively). ${ }^{69}$ Furthermore, at least in the US, prednisone and methylprednisolone are considerably cheaper compared to oral budesonide MMX [table 4] ${ }^{70}$ Thus a benefit/risk and cost evaluation in regard to the choice of steroid therapy for the individual patient should be performed before the start of therapy.

\section{Acknowledgments}

Source of funding: HH is supported by a grant of the National Health Institute (NIH) 1U01-DK092239-01

\section{References}

1. TRUELOVE SC, WITTS LJ. Cortisone and corticotrophin in ulcerative colitis. Br Med J. 1959; 1(5119):387-394. [PubMed: 13618646]

2. LENNARD-JONES JE, LONGMORE AJ, NEWELL AC, WILSON CW, JONES FA. An assessment of prednisone, salazopyrin, and topical hydrocortisone hemisuccinate used as out-patient treatment for ulcerative colitis. Gut. 1960; 1:217-222. [PubMed: 13760840]

3. TRUELOVE SC, WATKINSON G, DRAPER G. Comparison of corticosteroid and sulphasalazine therapy in ulcerative colitis. Br Med J. 1962; 2(5321):1708-1711. [PubMed: 13994348]

4. Faubion WA Jr, Loftus EV Jr, Harmsen WS, Zinsmeister AR, Sandborn WJ. The natural history of corticosteroid therapy for inflammatory bowel disease: A population-based study. Gastroenterology. 2001; 121(2):255-260. [PubMed: 11487534]

5. Katz JA. Treatment of inflammatory bowel disease with corticosteroids. Gastroenterol Clin North Am. 2004; 33(2):171-89, vii. [PubMed: 15177533]

6. Kornbluth A, Sachar DB, Practice Parameters Committee of the American College of Gastroenterology. Ulcerative colitis practice guidelines in adults: American college of gastroenterology, practice parameters committee. Am J Gastroenterol. 2010; 105(3):501-23. quiz 524. [PubMed: 20068560]

7. Ford AC, Bernstein CN, Khan KJ, et al. Glucocorticosteroid therapy in inflammatory bowel disease: Systematic review and meta-analysis. Am J Gastroenterol. 2011; 106(4):590-9. quiz 600. [PubMed: 21407179]

8. Brattsand R, Linden M. Cytokine modulation by glucocorticoids: Mechanisms and actions in cellular studies. Aliment Pharmacol Ther. 1996; 10(Suppl 2):81-90. discussion 91-2. [PubMed: 8899106]

9. Farrell RJ, Kelleher D. Glucocorticoid resistance in inflammatory bowel disease. J Endocrinol. 2003; 178(3):339-346. [PubMed: 12967327] 
10. LENNARD-JONES JE, MISIEWICZ JJ, CONNELL AM, BARON JH, JONES FA. Prednisone as maintenance treatment for ulcerative colitis in remission. Lancet. 1965; 1(7378):188-189. [PubMed: 14238045]

11. Nunes T, Barreiro-de Acosta M, Marin-Jimenez I, Nos P, Sans M. Oral locally active steroids in inflammatory bowel disease. J Crohns Colitis. 2013; 7(3):183-191. [PubMed: 22784947]

12. Lichtenstein GR, Hanauer SB, Sandborn WJ, Practice Parameters Committee of American College of Gastroenterology. Management of crohn's disease in adults. Am J Gastroenterol. 2009; 104(2): 465-83. quiz 464, 484. [PubMed: 19174807]

13. Rezaie A, Kuenzig ME, Benchimol EI, et al. Budesonide for induction of remission in crohn's disease. Cochrane Database Syst Rev. 2015; 6:CD000296. [PubMed: 26039678]

14. Ye Y, Pang Z, Chen W, Ju S, Zhou C. The epidemiology and risk factors of inflammatory bowel disease. Int J Clin Exp Med. 2015; 8(12):22529-22542. [PubMed: 26885239]

15. Grinspan A, Kornbluth A. Positioning therapy for ulcerative colitis. Curr Gastroenterol Rep. 2015; 17(8) 29-015-0454-0.

16. U.S. Food and Drug Administration. Drug approval package: Uceris (budesonide) $9 \mathrm{mg}$ tablets. http://www.accessdata.fda.gov/drugsatfda_docs/nda/2013/203634_uceris_toc.cfm. Updated 2013. Accessed 4/14, 2016

17. U.S. Food and Drug Administration. Uceris (budesonide) rectal foam. http:// www.accessdata.fda.gov/drugsatfda_docs/nda/2014/205613Orig1s000TOC.cfm. Updated 2015. Accessed 4/14/2016, 2016

18. Ryrfeldt A, Edsbacker S, Pauwels R. Kinetics of the epimeric glucocorticoid budesonide. Clin Pharmacol Ther. 1984; 35(4):525-530. [PubMed: 6705451]

19. Dahlberg E, Thalen A, Brattsand R, et al. Correlation between chemical structure, receptor binding, and biological activity of some novel, highly active, 16 alpha, 17 alpha-acetal-substituted glucocorticoids. Mol Pharmacol. 1984; 25(1):70-78. [PubMed: 6708937]

20. Hamedani R, Feldman RD, Feagan BG. Review article: Drug development in inflammatory bowel disease: Budesonide-a model of targeted therapy. Aliment Pharmacol Ther. 1997; 11(Suppl 3):98107. discussion 107-8. [PubMed: 9467984]

21. Kolkman JJ, Mollmann HW, Mollmann AC, et al. Evaluation of oral budesonide in the treatment of active distal ulcerative colitis. Drugs Today (Barc). 2004; 40(7):589-601. [PubMed: 15510233]

22. Brunner M, Ziegler S, Di Stefano AF, et al. Gastrointestinal transit, release and plasma pharmacokinetics of a new oral budesonide formulation. Br J Clin Pharmacol. 2006; 61(1):31-38. [PubMed: 16390349]

23. Klein S, Stein J, Dressman J. Site-specific delivery of anti-inflammatory drugs in the gastrointestinal tract: An in-vitro release model. J Pharm Pharmacol. 2005; 57(6):709-719. [PubMed: 15969925]

24. Jonsson G, Astrom A, Andersson P. Budesonide is metabolized by cytochrome P450 3A (CYP3A) enzymes in human liver. Drug Metab Dispos. 1995; 23(1):137-142. [PubMed: 7720517]

25. Dilger K, Schwab M, Fromm MF. Identification of budesonide and prednisone as substrates of the intestinal drug efflux pump P-glycoprotein. Inflamm Bowel Dis. 2004; 10(5):578-583. [PubMed: 15472518]

26*. Ryrfeldt A, Andersson P, Edsbacker S, Tonnesson M, Davies D, Pauwels R. Pharmacokinetics and metabolism of budesonide, a selective glucocorticoid. Eur J Respir Dis Suppl. 1982; 122:8695. (Provides pharmacokinetics data on budesonide-MMX). [PubMed: 6958498]

27. Silverman J, Otley A. Budesonide in the treatment of inflammatory bowel disease. Expert Rev Clin Immunol. 2011; 7(4):419-428. [PubMed: 21790284]

28. Nicholls A, Harris-Collazo R, Huang M, Hardiman Y, Jones R, Moro L. Bioavailability profile of uceris MMX extended-release tablets compared with entocort EC capsules in healthy volunteers. J Int Med Res. 2013; 41(2):386-394. [PubMed: 23569029]

29. Edsbacker S, Andersson T. Pharmacokinetics of budesonide (entocort EC) capsules for crohn's disease. Clin Pharmacokinet. 2004; 43(12):803-821. [PubMed: 15355126]

30. Medicines \& Healthcare products Regulatory Agency, UK. Public assessment report: Budenofalk 9mg gastro-resistant granules (budesonide) - PL 08637/0020. UK/H/2778/001/DC. http:// 
www.mhra.gov.uk/home/groups/par/documents/websiteresources/con111557.pdf. Updated 2011. Accessed 3/3, 2016

31. Nyman-Pantelidis M, Nilsson A, Wagner ZG, Borga O. Pharmacokinetics and retrograde colonic spread of budesonide enemas in patients with distal ulcerative colitis. Aliment Pharmacol Ther. 1994; 8(6):617-622. [PubMed: 7696451]

32*. Danielsson A, Edsbacker S, Lofberg R, et al. Pharmacokinetics of budesonide enema in patients with distal ulcerative colitis or proctitis. Aliment Pharmacol Ther. 1993; 7(4):401-407. (Updated pharmacokinetics data on budesonide enema). [PubMed: 8218754]

33*. Brunner M, Vogelsang H, Greinwald R, et al. Colonic spread and serum pharmacokinetics of budesonide foam in patients with mildly to moderately active ulcerative colitis. Aliment Pharmacol Ther. 2005; 22(5):463-470. (Updated pharmacokinetics data on budesonide foam). [PubMed: 16128685]

34*. Rubin DT, Sandborn WJ, Bosworth B, et al. Budesonide foam has a favorable safety profile for inducing remission in mild-to-moderate ulcerative proctitis or proctosigmoiditis. Dig Dis Sci. 2015; 60(11):3408-3417. (Provides safety data analysis for the use of budesonide foam in UC patients). [PubMed: 26386854]

35. Seidegard J. Reduction of the inhibitory effect of ketoconazole on budesonide pharmacokinetics by separation of their time of administration. Clin Pharmacol Ther. 2000; 68(1):13-17. [PubMed: 10945311]

36. Seidegard J, Randvall G, Nyberg L, Borga O. Grapefruit juice interaction with oral budesonide: Equal effect on immediate-release and delayed-release formulations. Pharmazie. 2009; 64(7):461465. [PubMed: 19694184]

37. Sherlock ME, Seow CH, Steinhart AH, Griffiths AM. Oral budesonide for induction of remission in ulcerative colitis. Cochrane Database Syst Rev. 2010; 10:CD007698. [PubMed: 20927762]

38*. Lofberg R, Danielsson A, Suhr O, et al. Oral budesonide versus prednisolone in patients with active extensive and left-sided ulcerative colitis. Gastroenterology. 1996; 110(6):1713-1718. (Only study with comparison between oral budesonide and systemic steroid in UC patients). [PubMed: 8964395]

$39^{* *}$. Gross V, Bunganic I, Belousova EA, et al. $3 \mathrm{~g}$ mesalazine granules are superior to $9 \mathrm{mg}$ budesonide for achieving remission in active ulcerative colitis: A double-blind, double-dummy, randomised trial. J Crohns Colitis. 2011; 5(2):129-138. (Only study with comparison between oral budesonide and 5-ASA in UC patients). [PubMed: 21453882]

40*. D'Haens GR, Kovacs A, Vergauwe P, et al. Clinical trial: Preliminary efficacy and safety study of a new budesonide-MMX(R) $9 \mathrm{mg}$ extended-release tablets in patients with active left-sided ulcerative colitis. J Crohns Colitis. 2010; 4(2):153-160. (Earlier trial assessing budesonide-MMX in UC). [PubMed: 21122499]

41**. Sandborn WJ, Travis S, Moro L, et al. Once-daily budesonide MMX(R) extended-release tablets induce remission in patients with mild to moderate ulcerative colitis: Results from the CORE I study. Gastroenterology. 2012; 143(5):1218-26.e1. (One of the two pivotal trials resulting in FDA approval of budesonide-MMX in UC patients). [PubMed: 22892337]

42**. Travis SP, Danese S, Kupcinskas L, et al. Once-daily budesonide MMX in active, mild-tomoderate ulcerative colitis: Results from the randomised CORE II study. Gut. 2014; 63(3):433441. (One of the two pivotal trials resulting in FDA approval of budesonide-MMX in UC patients). [PubMed: 23436336]

43*. Rubin D, Russell C, William S, et al. O-001 budesonide MMX(R) 9 mg for inducing remission in patients with mild-to-moderate ulcerative colitis not adequately controlled with oral 5-ASAs. Inflamm Bowel Dis. 2014; 20(Supplement 1):S1. (Assessed the efficacy of budesonide-MMX in particular subpopulation of UC patients who failed 5-ASA- available in abstract format only). [PubMed: 25834857]

44. Sandborn WJ, Danese S, D'Haens G, et al. Induction of clinical and colonoscopic remission of mild-to-moderate ulcerative colitis with budesonide MMX $9 \mathrm{mg}$ : Pooled analysis of two phase 3 studies. Aliment Pharmacol Ther. 2015; 41(5):409-418. [PubMed: 25588902]

45*. Sherlock ME, MacDonald JK, Griffiths AM, Steinhart AH, Seow CH. Oral budesonide for induction of remission in ulcerative colitis. Cochrane Database Syst Rev. 2015; 10:CD007698. 
(Cochrane review of the trials assessing the efficacy of oral budesonide in UC patients. also provided subgroup analysis). [PubMed: 26497719]

46*. Sandborn WJ, Danese S, Ballard ED, et al. Su2080 efficacy of budesonide MMx(r) 6 mg QD for the maintenance of remission in patients with ulcerative colitis: Results from a phase III, 12 month safety and extended use study. Gastroenterology. 2012; 142(5, Supplement 1):S-564. (Only study with maintenance data for oral budesonide-MMX in UC patients- available in abstract format only).

47. KELLER R, STOLL R, FOERSTER EC, GUTSCHE N, DOMSCHKE W. Oral budesonide therapy for steroid-dependent ulcerative colitis: A pilot trial. Aliment Pharmacol Ther. 1997; 11(6):1047-1052. [PubMed: 9663828]

48*. Danielsson A, Lofberg R, Persson T, et al. A steroid enema, budesonide, lacking systemic effects for the treatment of distal ulcerative colitis or proctitis. Scand J Gastroenterol. 1992; 27(1):9-12. (One of the earlier trials assessing the efficacy of rectal budesonide in patients with left-sided UC). [PubMed: 1736348]

49*. Hanauer SB, Robinson M, Pruitt R, et al. Budesonide enema for the treatment of active, distal ulcerative colitis and proctitis: A dose-ranging study. U.S. budesonide enema study group. Gastroenterology. 1998; 115(3):525-532. (Only study assessed the efficacy of different doses per application of rectal budesonide). [PubMed: 9721148]

$50 * *$. Sandborn WJ, Bosworth B, Zakko S, et al. Budesonide foam induces remission in patients with mild to moderate ulcerative proctitis and ulcerative proctosigmoiditis. Gastroenterology. 2015; 148(4):740-750.e2. (Results of the two pivotal studies assessing the efficacy of rectal budesonide foam on Uc and resulted in FDA approval). [PubMed: 25644096]

51*. Naganuma M, Aoyama N, Suzuki Y, et al. Twice-daily budesonide 2-mg foam induces complete mucosal healing in patients with distal ulcerative colitis. J Crohns Colitis. 2015 doi: jjv208 [pii]. (Provide comparison between BID and daily dosing of rectal budesonide for induction of remission in patients with left-sided UC).

$52 * *$. Lindgren S, Lofberg R, Bergholm L, et al. Effect of budesonide enema on remission and relapse rate in distal ulcerative colitis and proctitis. Scand J Gastroenterol. 2002; 37(6):705-710. (Only study with maintenance data on the efficacy of rectal budesonide in left sided UC). [PubMed: 12126250]

53*. Gross V, Bar-Meir S, Lavy A, et al. Budesonide foam versus budesonide enema in active ulcerative proctitis and proctosigmoiditis. Aliment Pharmacol Ther. 2006; 23(2):303-312. (One of the trials comparing the efficacy of rectal budesonide to other forms of rectal corticosteroids). [PubMed: 16393311]

54*. Danielsson A, Hellers G, Lyrenas E, et al. A controlled randomized trial of budesonide versus prednisolone retention enemas in active distal ulcerative colitis. Scand J Gastroenterol. 1987; 22(8):987-992. (One of the trials comparing the efficacy of rectal budesonide to other forms of rectal corticosteroids). [PubMed: 3317784]

55*. Matzen P. Budesonide enema in distal ulcerative colitis. A randomized dose-response trial with prednisolone enema as positive control. the danish budesonide study group. Scand J Gastroenterol. 1991; 26(12):1225-1230. (One of the trials comparing the efficacy of rectal budesonide to other forms of rectal corticosteroids). [PubMed: 1763292]

56*. Lofberg R, Ostergaard Thomsen O, Langholz E, et al. Budesonide versus prednisolone retention enemas in active distal ulcerative colitis. Aliment Pharmacol Ther. 1994; 8(6):623-629. (One of the trials comparing the efficacy of rectal budesonide to other forms of rectal corticosteroids). [PubMed: 7696452]

57*. Tarpila S, Turunen U, Seppala K, et al. Budesonide enema in active haemorrhagic proctitis-a controlled trial against hydrocortisone foam enema. Aliment Pharmacol Ther. 1994; 8(6):591595. (One of the trials comparing the efficacy of rectal budesonide to other forms of rectal corticosteroids). [PubMed: 7696447]

58*. Porro GB, Prantera C, Campierit M, et al. Comparative trial of methylprednisolone and budesonide enemas in active distal ulcerative colitis. Eur J Gastroenterol Hepatol. 1994; 6(2): 125-130. (One of the trials comparing the efficacy of rectal budesonide to other forms of rectal corticosteroids). 
59*. Bar-Meir S, Fidder HH, Faszczyk M, et al. Budesonide foam vs. hydrocortisone acetate foam in the treatment of active ulcerative proctosigmoiditis. Dis Colon Rectum. 2003; 46(7):929-936. (One of the trials comparing the efficacy of rectal budesonide to other forms of rectal corticosteroids). [PubMed: 12847368]

60*. Lemann M, Galian A, Rutgeerts P, et al. Comparison of budesonide and 5-aminosalicylic acid enemas in active distal ulcerative colitis. Aliment Pharmacol Ther. 1995; 9(5):557-562. (One of the trials comparing the efficacy of rectal budesonide to rectal 5-ASA). [PubMed: 8580278]

61*. Hartmann F, Stein J, BudMesa-Study Group. Clinical trial: Controlled, open, randomized multicentre study comparing the effects of treatment on quality of life, safety and efficacy of budesonide or mesalazine enemas in active left-sided ulcerative colitis. Aliment Pharmacol Ther. 2010; 32(3):368-376. (One of the trials comparing the efficacy of rectal budesonide to rectal 5ASA). [PubMed: 20491741]

62*. Lichtenstein GR, Travis S, Danese S, et al. Budesonide MMX for the induction of remission of mild to moderate ulcerative colitis: A pooled safety analysis. J Crohns Colitis. 2015; 9(9):738746. (Provide safety data of the new budesonide-MMX formulation). [PubMed: 26094251]

63. Lichtenstein GR. Budesonide multi-matrix for the treatment of patients with ulcerative colitis. Dig Dis Sci. 2016; 61(2):358-370. [PubMed: 26541989]

64. Danese S, Siegel CA, Peyrin-Biroulet L. Review article: Integrating budesonide-MMX into treatment algorithms for mild-to-moderate ulcerative colitis. Aliment Pharmacol Ther. 2014; 39(10):1095-1103. [PubMed: 24641622]

65. Gionchetti P, Pratico C, Rizzello F, et al. The role of budesonide-MMX in active ulcerative colitis. Expert Rev Gastroenterol Hepatol. 2014; 8(3):215-222. [PubMed: 24502535]

66. Safdi M, DeMicco M, Sninsky C, et al. A double-blind comparison of oral versus rectal mesalamine versus combination therapy in the treatment of distal ulcerative colitis. Am J Gastroenterol. 1997; 92(10):1867-1871. [PubMed: 9382054]

67. Kuenzig ME, Rezaie A, Seow CH, et al. Budesonide for maintenance of remission in crohn's disease. Cochrane Database Syst Rev. 2014; 8:CD002913. [PubMed: 25141071]

68. Herfarth H, Gross V, Andus T, et al. Analysis of the therapeutic efficacy of different doses of budesonide in patients with active crohn's ileocolitis depending on disease activity and localization. Int J Colorectal Dis. 2004; 19(2):147-152. [PubMed: 13680283]

69. Bebb JR, Scott BB. How effective are the usual treatments for ulcerative colitis? Aliment Pharmacol Ther. 2004; 20(2):143-149. [PubMed: 15233693]

70. GoodRx. http://www.goodrx.com/. Updated 2016. Accessed 3/3, 2016 


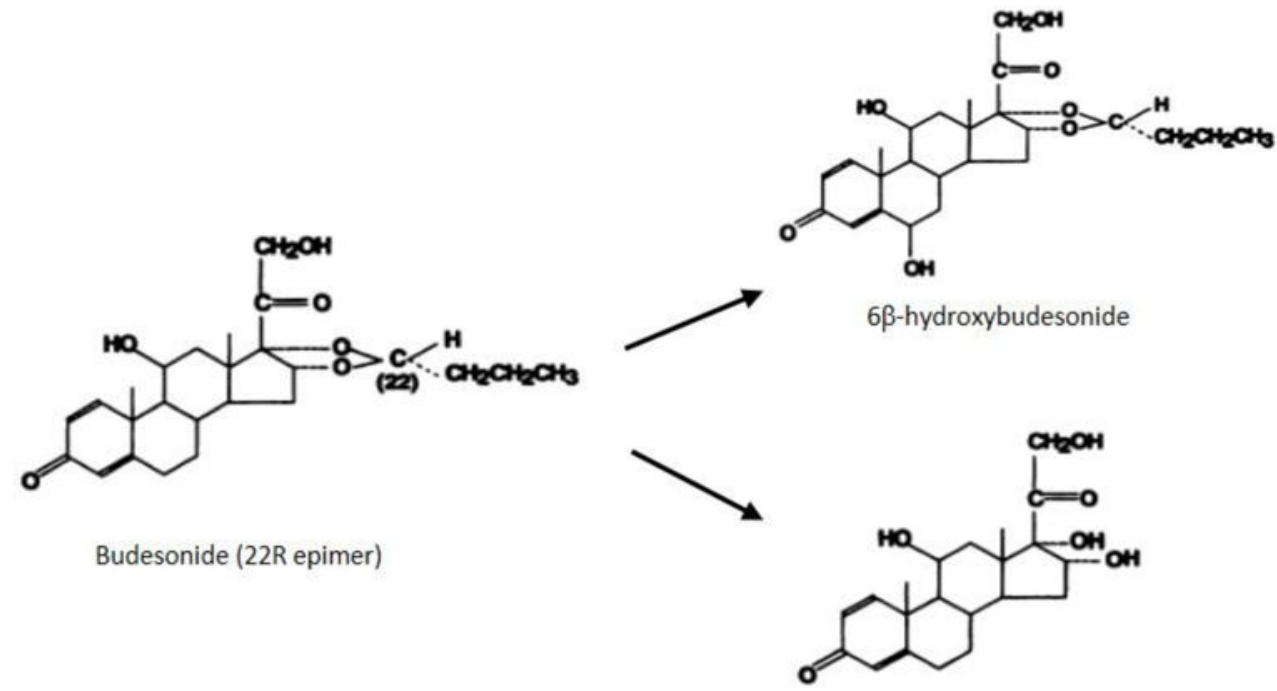

$16 \alpha$-hydroxyprednisolone

Figure 1. Molecular structure of Budesonide and its two metabolites

Figure adapted with permission from: G Jönsson, A Aström, and P Andersson, Budesonide is metabolized by cytochrome P450 3A (CYP3A) enzymes in human liver, Drug Metab Dispos January 1995 23:137-14218 
20

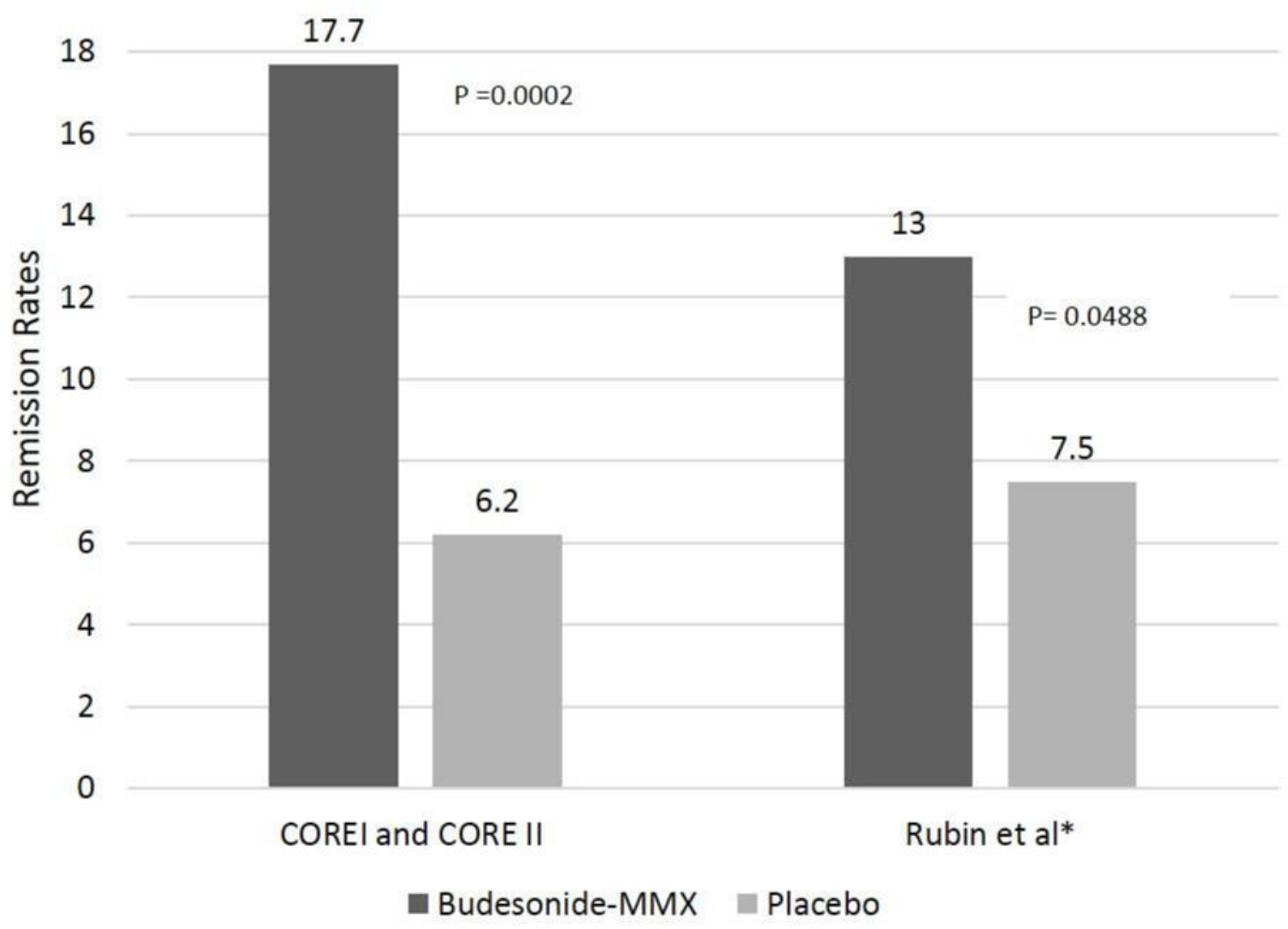

Figure 2.

Rates of remission (clinical and endoscopic) reported from combined CORE I and CORE II trials and Rubin et al study 


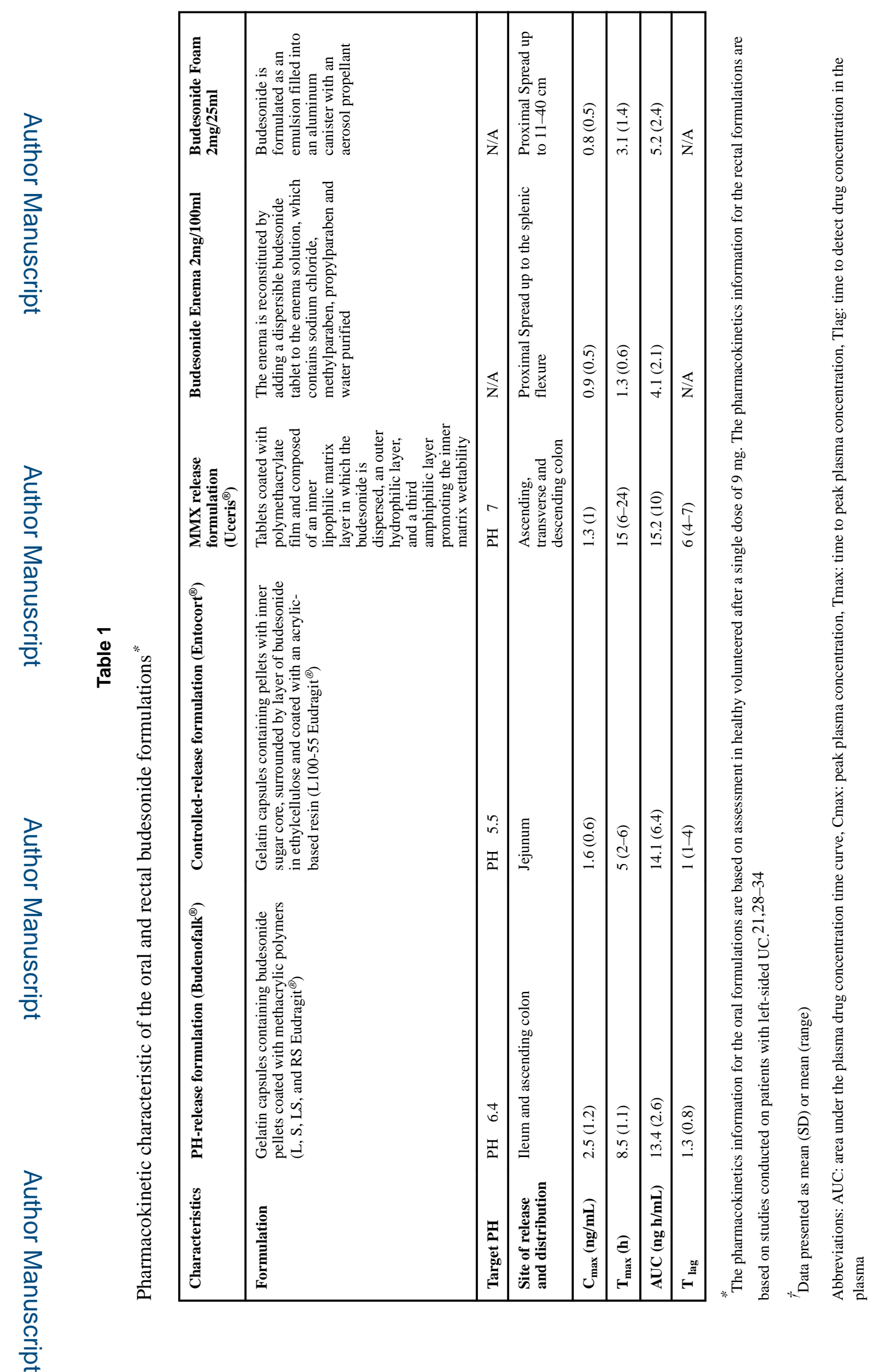

Expert Opin Pharmacother. Author manuscript; available in PMC 2017 August 01. 


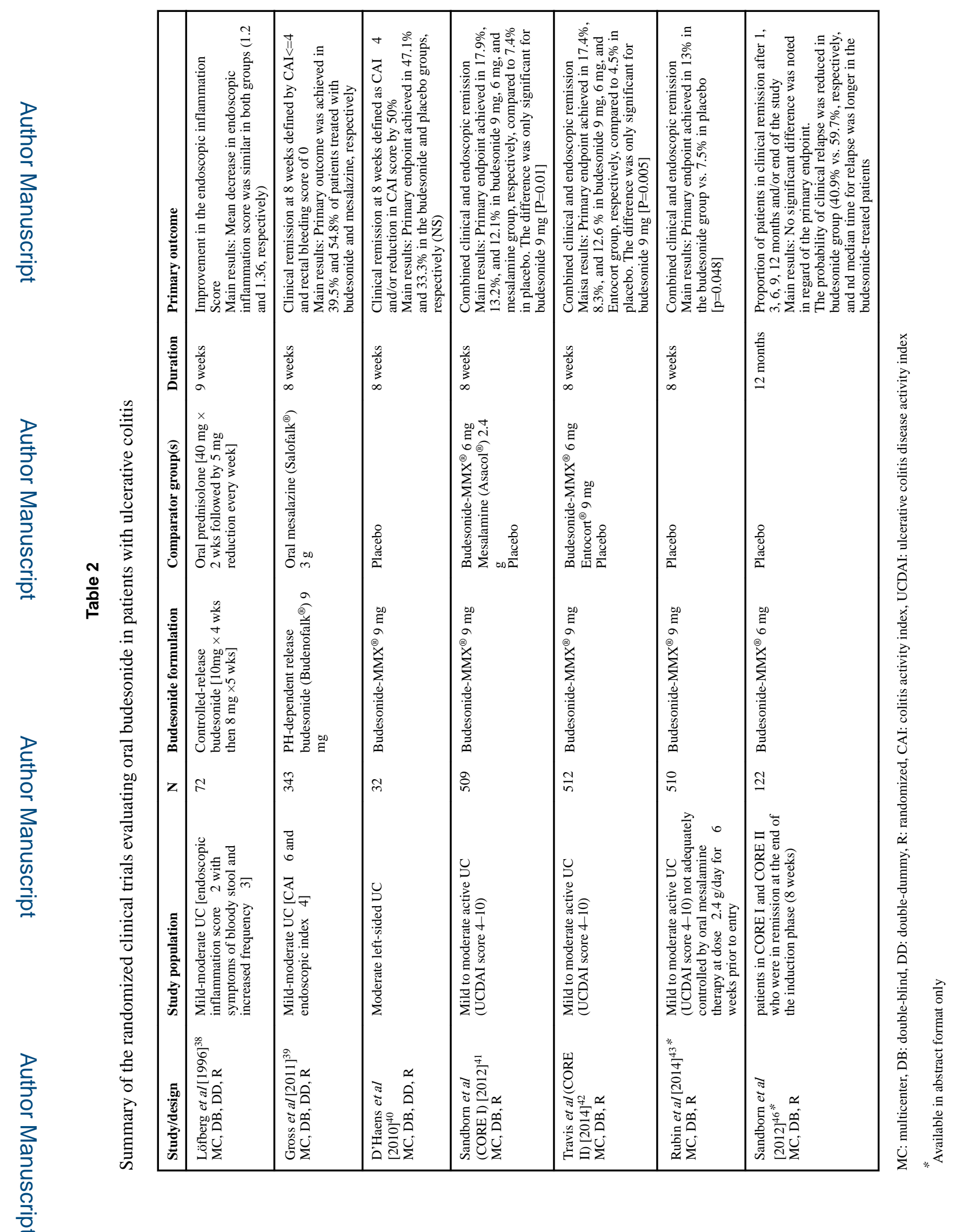

Expert Opin Pharmacother. Author manuscript; available in PMC 2017 August 01. 

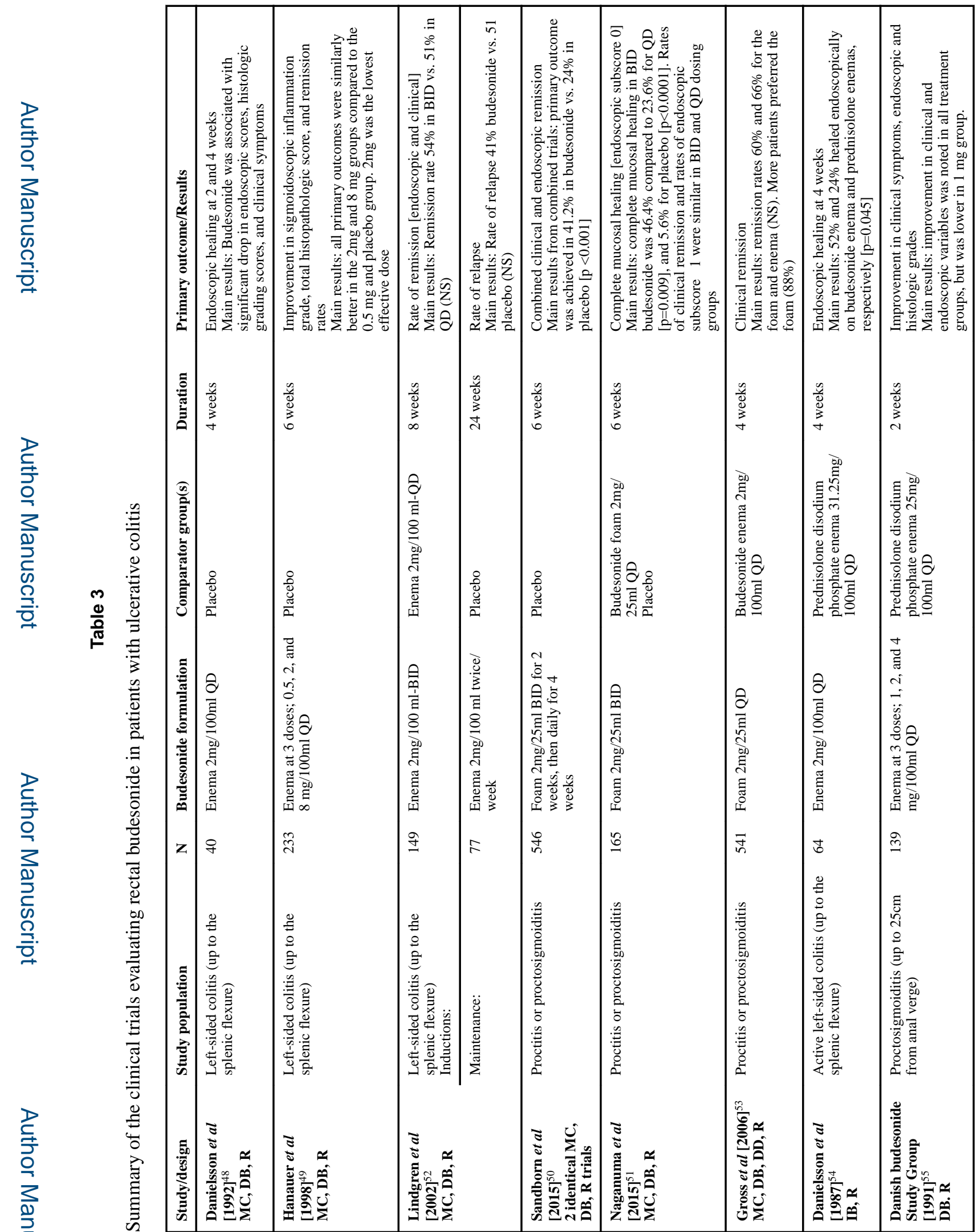

Expert Opin Pharmacother. Author manuscript; available in PMC 2017 August 01. 


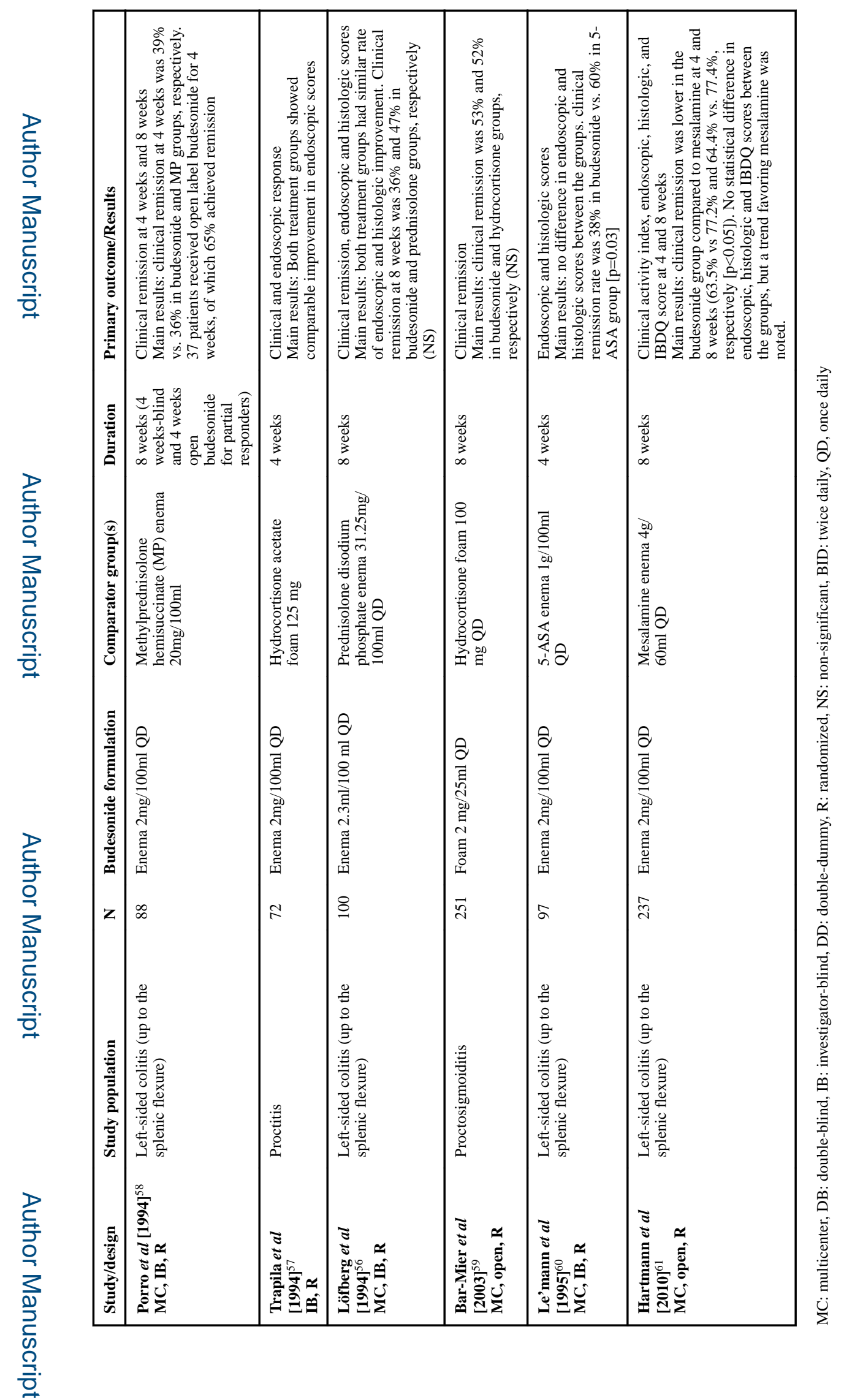

Expert Opin Pharmacother. Author manuscript; available in PMC 2017 August 01. 


\section{Table 4}

Price range of commonly used oral corticosteroids in IBD patients compared to budesonide-MMX (Uceris ${ }^{\circledR}$ ) in the US

\begin{tabular}{|ll|}
\hline Corticosteroids & Price (US dollars)* \\
\hline Budesonide-MMX (Uceris $^{\circledR}$ ) 9mg (30 tablets) & $\$ 1600-1700$ \\
\hline Prednisone 20 mg (100 tablets) & $\$ 11-40$ \\
\hline Methylprednisolone 16mg (100 tablets) & $\$ 120-300$ \\
\hline
\end{tabular}

The prices vary based on the insurance carrier, pharmacy, and the individual State. The numbers provided in the table were obtained from the GoodRx website 70 